\title{
Cucurmosin induces apoptosis of BxPC-3 human pancreatic cancer cells via inactivation of the EGFR signaling pathway
}

\author{
BAOMING ZHANG ${ }^{1}$, HEGUANG HUANG $^{1}$, JIEMING XIE ${ }^{2}$, CHUNSEN XU $^{1}$, MINGHUANG CHEN ${ }^{3}$, \\ CONGFEI WANG ${ }^{1}$, AIQIN YANG ${ }^{2}$ and QIANG YIN ${ }^{1}$ \\ ${ }^{1}$ Department of General Surgery, Union XieHe Hospital, Fujian Medical University; ${ }^{2}$ Department of Pharmacology, \\ Fujian Medical University; ${ }^{3}$ State Structural Chemistry Key Laboratory of Fujian Institute of Research \\ on Structure of Matter, Chinese Academy of Sciences, Fuzhou, Fujian Province, P.R. China
}

Received October 7, 2011; Accepted November 14, 2011

DOI: $10.3892 /$ or.2011.1573

\begin{abstract}
Pancreatic cancer remains the fourth most common cause of cancer-related death in the United States. Potent therapeutic strategies are urgently needed for pancreatic cancer. Cucurmosin is a novel type 1 ribosome-inactivating protein (RIP) isolated from the sarcocarp of Cucurbita moschata (pumpkin). Due to its cytotoxicity, cucurmosin can inhibit tumor cell proliferation through induction of apoptosis on tumor cells, but the specific mechanism is still unclear. We explored the function of cucurmosin in BxPC-3 pancreatic cancer cells using multiple cellular and molecular approaches such as 3-(4,5-dimethylthiazol-2-yl)-2,5-diphenyltetrazolium bromide assay, flow cytometry, reverse transcription polymerase chain reaction (RT-PCR), Western blotting and transmission electron microscopy for observing typical changes and formation of apoptotic bodies. We found that cucurmosin inhibited the proliferation of BxPC-3 cells in a time- and dose-dependent manner, and increased the cell population in the G0-G1 phase. With increasing concentration of cucurmosin, the expression of EGFR, p-PI3K, Akt, p-Akt, mTOR, p-mTOR, P70S6K- $\alpha$, p-P70S6K- $\alpha, 4 \mathrm{E}-\mathrm{BP} 1$ and p-4E-BP1 at the protein level was decreased, whereas the expression of $\mathrm{p}$-Bad and caspase- 9 was elevated. However, the mRNA expression of EGFR did not change. These findings suggest that cucurmosin can downregulate the expression of EGFR by targeting. Cucurmosin induces the apoptosis of BxPC-3 pancreatic cancer cells via the $\mathrm{PI} 3 \mathrm{~K} / \mathrm{Akt} / \mathrm{mTOR}$ signaling pathway.
\end{abstract}

Correspondence to: Dr Heguang Huang, Department of General Surgery, Union XieHe Hospital, Fujian Medical University, 29 Xinquan Road, Fuzhou 350001, Fujian Province, P.R. China

E-mail: hhuang2@yahoo.com.cn

Dr Jieming Xie, Department of Pharmacology, Fujian Medical University, 88 Jiaotong Road, Fuzhou 350004, Fujian Province, P.R. China

E-mail: xiejm1@sina.com

Key words: pancreatic carcinoma, cucurmosin, EGFR, PI3K/Akt, apoptosis

\section{Introduction}

Pancreatic cancer is the fourth leading cause of cancer related deaths among men and women with an approximately 43,140 new cases and 36,800 in 2010 in United States (1). Patients diagnosed with pancreatic cancer typically have a poor prognosis. For patients at all stages, the 1- and 5-year survival rates are only $23 \%$ and $6 \%$, respectively (2), because a majority of pancreatic cancer at the time of diagnosis is advanced and relative lack of early disease-specific symptoms (3). Since 1997, gemcitabine established its unshakable status as first-line therapy for advanced pancreatic cancer (4). In the past 10 years, Gemcitabine, with or without erlotinib, has been the standard chemotherapy in this setting but the benefit is only modest. A significant amount of studies on gemcitabine-based combinations chemotherapy, such as gemcitabine with fluorouracil, capecitabine, cisplatin, e.g., have not produced clear survival benefit (5). Therefore, the novel strategies are clearly needed.

The ribosome-inactivating proteins (RIPs) are RNA $\mathrm{N}$-glycosidases $(6,7)$ which inactivate ribosomes by sitespecifically cleaving the single $\mathrm{N}-\mathrm{C}$ glycosidic bond between adenine and ribose at A4324 in the $28 \mathrm{~S}$ rRNA, thus irreversibly inactivating ribosomes for protein synthesis. Based on the structure of the genes and mature proteins, RIPs can be classified into 3 types (8). Type 1; RIPs are single-chained proteins with a molecular weight of about $30 \mathrm{Kda}$. They are potent inhibitors of protein synthesis in the cell-free system, but are relatively non-toxic to intact cell. Type 2; RIPs are double -chained proteins which consist of an A-chain (catalytic subunit) corresponding to type 1 RIPs and a B-chain corresponding to lectin, linked by disulfide bond. The B-chain binds to galactosy1-terminated receptors on the target cell surface, facilitating the entry of the A-chain into the cytoplasm of the cell. Thus, some, but not all, type 2 RIPs are more potent toxin than type 1 RIPs because the latter can only enter into cells with difficulty. Type 3; RIPs is a kind of jasmonateinduced protein comprised of an N-terminal domain similar to other type 1 RIPs and an unrelated C-terminal domain of unknown function (9). Most RIPs are glycoproteins, with varying amount and type of sugars (10).

We isolate and purify cucurmosin from the sarcocarp of Cucurbita moschata (pumpkin). The weight of cucurmosin 
is about $28 \mathrm{KDa}$. Cucurmosin belongs to type $1 \mathrm{RIPs}$ and possesses an rRNA N-glycosidase activity (11). Significantly, it can inhibit the proliferation of cancer cells, through the induction of apoptosis $(12,13,14)$. In this study, we firstly investigated that cucurmosin can inhibit the proliferation and induce the apoptosis of human pancreatic cancer cell BxPC-3 by down-regulating the expression of EGFR at the protein level, but not at the gene level, and inactivate the downstream of EGFR, namely PI3K/Akt/mTOR signaling pathway.

\section{Materials and methods}

Antibodies and reagents. The primary rabbit polyclonal antibodies for EGFR (1:1000), Akt (1:1000), p-Akt (1:500), mTOR (1:1000), p-mTOR (1:1000), P70S6K- $\alpha$ (1:500), p-P70S6K- $\alpha$ (1:500), 4E-BP1 (1:500), p-4E-BP1 (1:750), and caspase-9 (1:1000) were obtained from BioWorld Technology, Inc. The primary rabbit monoclonal antibodies for p-PI3K (1:1000), Ras (1:500) and p-Bad (1:500) were obtained from Cell Signaling Technology. Cucurmosin that its purity was 97\% was offered by Minghuang Chen Pro. (State Structural Chemistry Key Laboratory of Fujian Institute of Research on Structure of Matter, Chinese Academy of Sciences). All secondary antibodies were purchased from Beyotime Institute of Biotechnology (Beyotime, China). 3-(4,5-Dimethylthiazol-2yl)-2,5-diphenyltetrazolium bromide (MTT) was obtained from Sigma St. Louis, MO.

Cell line and cell culture. Human pancreatic cancer cell line BxPC-3 was purchased from the Cell Bank of Type Culture Collection of Chinese Academy of Sciences (Shanghai, China), and cultured in RPMI-1640 media (Invitrogen, Carlsbad, CA) supplemented with $10 \%$ fetal bovine serum (FBS) (Gibco) and $1 \%$ penicillin and streptomycin in a humidified cell culture incubator with $5 \% \mathrm{CO}_{2}$ at $37^{\circ} \mathrm{C}$, and passed every 2-3 days to maintain logarithmic growth.

Cell growth inhibition studies by MTT assay. Human pancreatic cancer BxPC-3 cells $\left(6 \times 10^{3} /\right.$ well $\left./ 100 \mu \mathrm{l}\right)$ were seeded in 96-well culture plates and incubated for $24 \mathrm{~h}$, and then were treated with $0.03125,0.0625,0.125,0.25,0.5,1$ or $2 \mu \mathrm{M}$ cucurmosin for $24,48,72 \mathrm{~h}$. Control cells were supplemented with $100 \mu 1$ RPMI-1640 culture medium. After treatment, cells were incubated with MTT $20 \mu \mathrm{l}(0.5 \mathrm{mg} / \mathrm{ml})$ at $37^{\circ} \mathrm{C}$ for $4 \mathrm{~h}$, and subsequently moved the culture medium and added dimethyl sulfoxide (DMSO) $200 \mu \mathrm{l}$. The spectrophotometric absorbance of the samples at $570 \mathrm{~nm}$ wavelength was measured by Multiskan MK3 microplate reader (Thermo Scientific). Results were blotted as the mean \pm standard deviation. Each experiment was repeated 3 times.

Cellular shape changes by transmission electron microscope. BxPC-3 cells $\left(3 \times 10^{5} /\right.$ well) were seeded in 6 -well plates. After incubation for $24 \mathrm{~h}$, cells were treated with $1 \mu \mathrm{M}$ cucurmosin for $72 \mathrm{~h}$. Control cells were supplemented with RPMI-1640 culture medium. Cells $\left(1 \times 10^{6}\right)$ were harvested and washed 3 times with PBS, then centrifuged at $15,000 \mathrm{x}$ g for $15 \mathrm{~min}$, and subsequently fixed in $4 \%$ glutaraldehyde for $2 \mathrm{~h}$. After fixation, samples were fixed in $1 \%$ osmic acid for $2 \mathrm{~h}$, then gradually dehydrated by acetone and embedded with epoxy

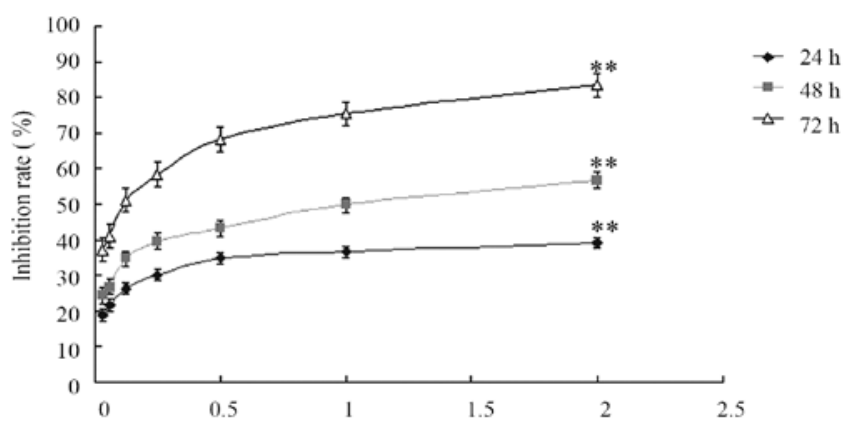

Figure 1. Inhibitory effect of cucurmosin on human pancreatic cancer cells. BxPC-3 cells were treated with various concentrations $(0.03125,0.0625$, $0.125,0.25,0.5,1$ and $2 \mu \mathrm{M})$ of cucurmosin for 24,48 and $72 \mathrm{~h}$. MTT assay was performed. The data shown are the means \pm SEM of 3 separate experiments.** $\mathrm{P}<0.05$ vs. control.

resin. Cells shape were observed under transmission electron microscope.

Flow cytometry cell cycle and apoptosis analysis. BxPC-3 cells $\left(2 \times 10^{6} /\right.$ well $)$ were seeded in $90 \mathrm{~mm}$ plates. After attached for $24 \mathrm{~h}$, cells were treated without control or with $0.0625,0.25$ and $1 \mu \mathrm{M}$ cucurmosin for $72 \mathrm{~h}$. Cells $\left(1 \times 10^{6}\right)$ were harvested and washed 3 times with PBS, and then respectively analyzed for their DNA content and apoptosis ratio by FACSCalibur (Becton-Dickinson, Mountain View, CA) using Cell Cycle Detection kit and Annexin V-FITC Apoptosis Detection kit (KeyGEN, Nanjing, China) according to the protocol of the manufacturer.

Reverse transcription polymerase chain reaction (RT-PCR) analysis for the expression of EGFR $m R N A$ studies. BxPC-3 cells $\left(2 \times 10^{6} /\right.$ well $)$ were seeded in $90 \mathrm{~mm}$ plates. After attached for $24 \mathrm{~h}$, cells were treated without control or with $0.0625,0.25$ and $1 \mu \mathrm{M}$ cucurmosin for $72 \mathrm{~h}$. Cells $\left(1 \times 10^{6}\right)$ were harvested and washed 3 times with PBS. The total-RNA from each sample was isolated by TRIzol (Invitrogen) and purified by RNeasy mini kit and RNase-free DNase Set (Qiagen, Valencia, CA) according to the protocol of the manufacturer. One microgram of total-RNA from each sample was subjected to first strand combinational DNA (cDNA) synthesis using the TaqMan reverse transcriptase (RT) reagent kit (Fermentas) in a total volume of $20 \mu \mathrm{l}$, including 6.25 units of MultiScribe RT and 25 pmol of random hexamers. RT reaction was done at $25^{\circ} \mathrm{C}$ for $5 \mathrm{~min}$, followed by $42^{\circ} \mathrm{C}$ for $60 \mathrm{~min}$, and $70^{\circ} \mathrm{C}$ for $5 \mathrm{~min}$. After the RT, the polymerase chain reaction was undertaken. The primers used in this study are as follows: EGFR forward, 5'-TGCAGAATCCTGTCTATCACAATCA-3' and reverse, 5'-AGGGCTGTCGAATGTGCTGTT-3'; $\beta$-actin forward, 5'-TTCCTGGGCATGGAGTCCTGTGG-3' and reverse, 5'- CG CCTAGAAGCATTTGCGGTGG-3'. The PCR reaction was used for a total volume of $20 \mu \mathrm{l}$, including $2 \mu \mathrm{l}$ EGFR cDNA or $1 \mu 1 \beta$-actin cDNA. The thermal profile for PCR was $94^{\circ} \mathrm{C}$ for $5 \mathrm{~min}, 94^{\circ} \mathrm{C}$ for $45 \mathrm{sec}, 60^{\circ} \mathrm{C}$ for $45 \mathrm{sec}, 72^{\circ} \mathrm{C}$ for $90 \mathrm{sec}$ and $72^{\circ} \mathrm{C}$ for $5 \mathrm{~min}$, by 35 cycles. Each sample was tested in duplicated.

Western blot analysis. BxPC- 3 cells $\left(2 \times 10^{6} /\right.$ well) were seeded $90-\mathrm{mm}$ plates. After attached for $24 \mathrm{~h}$, cells were treated 

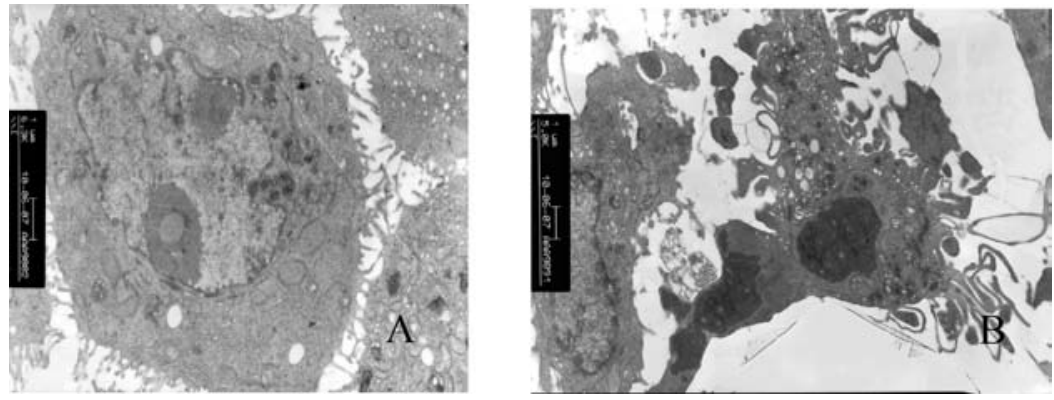

Figure 2. Morphologic change of pancreatic cancer BxPC-3 cells at $72 \mathrm{~h}$ after culture in 2 groups under transmission electron microscope. (A) BxPC-3 cells were treated without cucurmosin and supplemented with RPMI-1640 culture medium for $72 \mathrm{~h}$ (Control). (B) BxPC-3 cells were treated with $1 \mu \mathrm{M}$ cucurmosin for $72 \mathrm{~h}$.

A

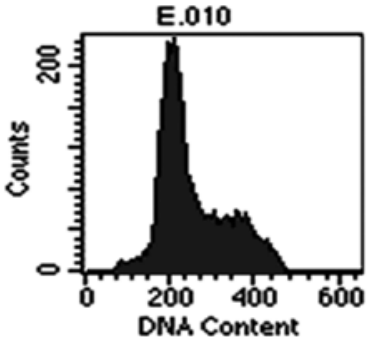

Control

B

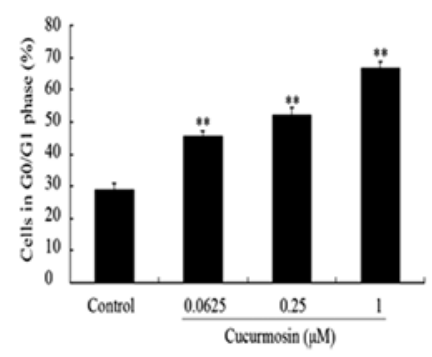

E.011

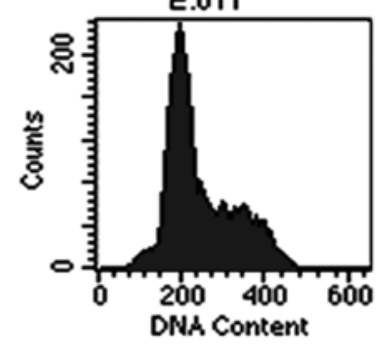

Cucurmosin $(0.0625 \mu 10$

C

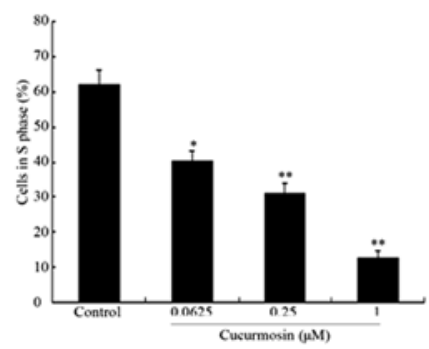

E.012

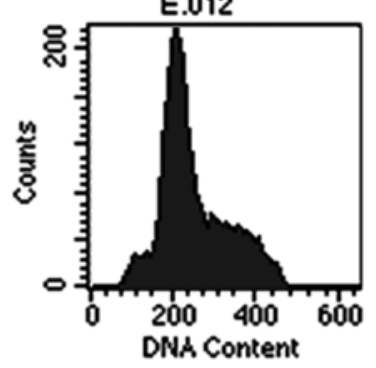

Cucurnosin $(0.25 \mu \mathrm{V})$

D

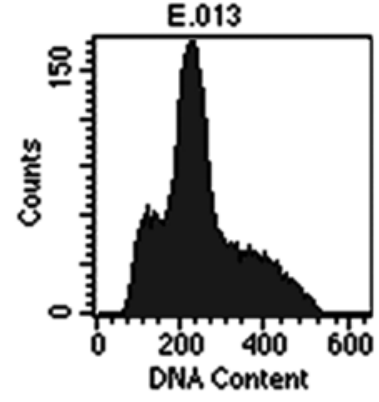

Cucurmosin $(1 \mu \mathrm{Mn})$

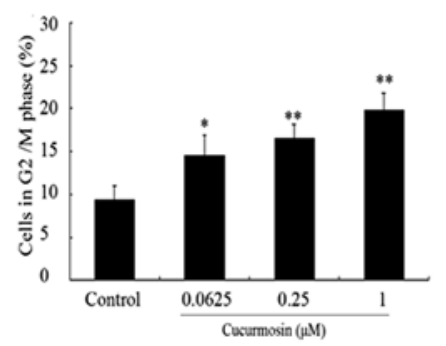

Figure 3. Flow cytometric analysis of cucurmosin-induced cell cycle arrest. After treatment without (control) or with $0.0625,0.25$ and $1 \mu \mathrm{M}$ cucurmosin for $72 \mathrm{~h}, \mathrm{BxPC}-3$ cells were harvested $\left(1 \times 10^{6}\right)$ and fixed with $1 \mathrm{ml}$ of $70 \%$ ice-cold ethanol at $4^{\circ} \mathrm{C}$. And then cells were stained with propidium iodide and analyzed by flow cytometric. (A) The diploid peek of apoptosis was detected in response to cucurmosin. The percentages of total cells in the G0/G1 phase (B), S phase (C) and G2/M phase (D) are shown as the means \pm SEM of 3 separate experiments. ${ }^{*} \mathrm{P}<0.01$ vs. control, ${ }^{* *} \mathrm{P}<0.05$ vs. control.

with $0,0.0625,0.25$ and $1 \mu \mathrm{M}$ cucurmosin for $72 \mathrm{~h}$. Cells were harvested and washed 3 times with PBS. Each sample was lysed in lysis buffer [50 mmol/1 Tris- $\mathrm{HCl}, \mathrm{PH} \mathrm{7.5,}$ $100 \mathrm{mmol} / 1 \mathrm{NaCl}, 1 \mathrm{mmol} / \mathrm{l}$ ethylenediamine tetraacetic acid (EDTA), 0.5\% Nonidet P-40, 0.5\% Triton X-100, 2.5 mmol/1 sodium orthovanadate, $10 \mu \mathrm{l} / \mathrm{ml}$ protease inhibitor cocktail and $1 \mathrm{mmol} / \mathrm{l}$ phenylmethylsulfonyl fluoride (PMSF)] by incubating for $15 \mathrm{~min}$ at $4^{\circ} \mathrm{C}$, and centrifuged at $12,000 \mathrm{~g}$ for $15 \mathrm{~min}$. Protein concentrations were measured by BCA assay. Total proteins were fractionated by sodium dodecyl sulfate-polyacrylamide gel electrophoresis (SDS-PAGE), and the gel was transferred onto nitrocellulose membrane. The membranes were blocked using 5\% BSA, and then incubated with specific primary antibodies. The immunocomplexes were incubated with the appropriate horseradish peroxidaseconjugated anti-rabbit secondary antibodies, and then detected using the Luminata Forte Western HRP substrate (Millipore).
Statistical analysis. Statistical analysis was performed with the statistical analysis software SPSS 13.0. Comparisons were performed using the Student's t-test between 2 groups. Results are presented as means \pm SEM. $\mathrm{P}<0.05$ was considered to indicate significant difference.

\section{Results}

Cucurmosin inhibits the proliferation and induces the apoptosis on human pancreatic cancer BxPC-3 cells. Besides rRNA N-glycosidase activity, cucurmosin exhibits strong cytotoxicity to cancer cells. To test these properties, we performed the MTT assay. After pancreatic cancer BxPC-3 cells were treated with $0.03125,0.0625,0.125,0.25,0.5,1$ or $2 \mu \mathrm{M}$ cucurmosin for 24,48 or $72 \mathrm{~h}$, the proliferation was inhibited in a time and dose-dependent manner in BxPC-3 cells (Fig. 1). The $\mathrm{IC}_{50}$ values for 24,48 , and $72 \mathrm{~h}$ were $1.45 \pm 2.14,0.54 \pm 1.78$, $0.22 \pm 0.69 \mu \mathrm{M}$, respectively $(\mathrm{P}<0.05)$. 
A

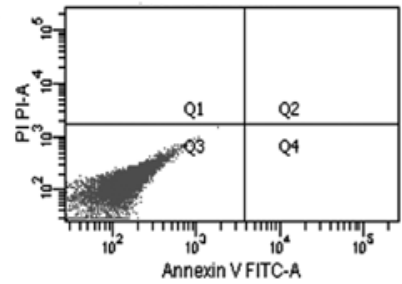

Control

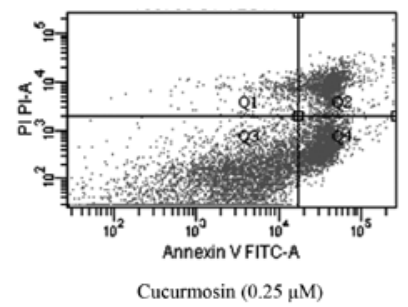

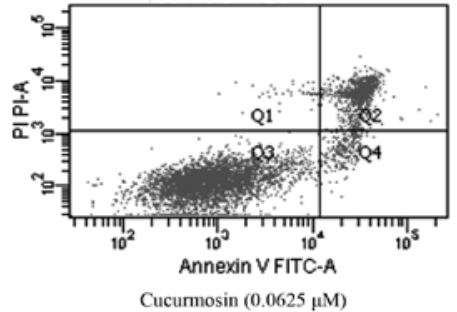

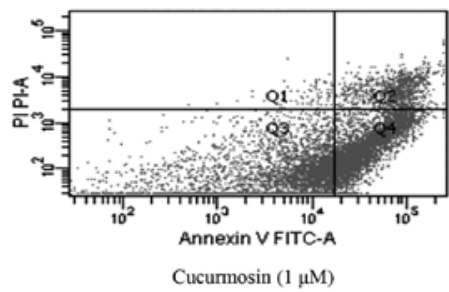

B

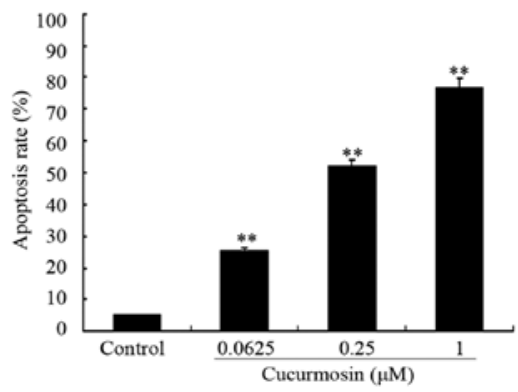

Figure 4. Flow cytometric analysis of cucurmosin-induced cell apoptosis rate. After treatment without control or with $0.0625,0.25$ or $1 \mu \mathrm{M}$ cucurmosin for $72 \mathrm{~h}, \mathrm{BxPC}-3$ cells were harvested $\left(1 \times 10^{6}\right)$ and fixed with $1 \mathrm{ml}$ of $70 \%$ ice-cold ethanol at $4^{\circ} \mathrm{C}$. And then samples were analyzed by flow cytometry according to the protocol of the manufacturer. (A) The apoptosis was detected in response to various concentrations of cucurmosin. (B) The percentages of apoptotic cells are shown as the means \pm SEM of 3 separate experiments. ${ }^{* *} \mathrm{P}<0.05$ vs. control.

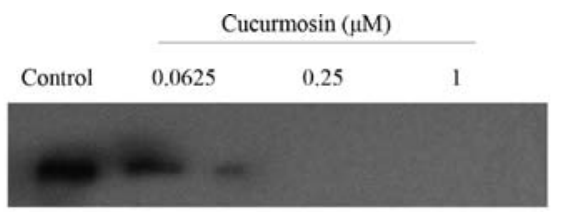

EGFR

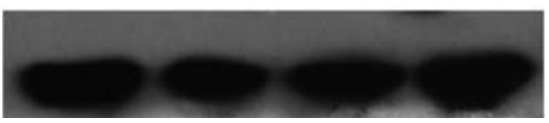

$\beta$-Actin

Figure 5. Cucurmosin down-regulates the protein expression of EGFR. After pancreatic cancer BxPC-3 cells were treated without (control) or with various concentrations of cucurmosin for $72 \mathrm{~h}$. Cells were harvested and the total protein fraction was extracted, separated on SDS-PAGE, and exposed to specific antibodies using Western blotting as described in Materials and methods. With increasing concentrations of cucurmosin, the protein expression of EGFR was gradually reduced. The results shown are representatives of 3 independent experiments

To evaluate whether cucurmosin inhibited the proliferation in BxPC-3 cells through the induction of apoptosis, transmission electron microscopy was used to examine cell shape. Consistently, after BxPC-3 cells were treated with $1 \mu \mathrm{M}$ cucurmosin for $72 \mathrm{~h}$, cells showed typical features of apoptosis, such as destroyed cellular structures, collapsed cells, and the appearance of a significant number of apoptotic bodies in BxPC-3 cells (Fig. 2). To further evaluate the apoptosis in BxPC-3 cells, DNA content and apoptosis ratios were analyzed by flow cytometry using the Cell Cycle Detection kit and the Annexin V-FITC Apoptosis Detection kit. We found that the cell cycle of pancreatic cancer BxPC-3 cell was arrested in $\mathrm{G} 0$ / G1 phase (Fig. 3), and the apoptosis rates without (control) or with $0.0625,0.25,1 \mu \mathrm{M}$ cucurmosin for $72 \mathrm{~h}$ were $5.31 \pm 0.21 \%$, $25.17 \pm 1.32 \%, 51.79 \pm 2.32 \%$ and $76.57 \pm 3.25 \%$, respectively (Fig. 4) $(\mathrm{P}<0.05)$.

Cucurmosin down-regulates EGFR protein expression and inactivates the PI3K/Akt/mTOR signaling pathway. EGFR mutations are rare in pancreatic tumors and have not been

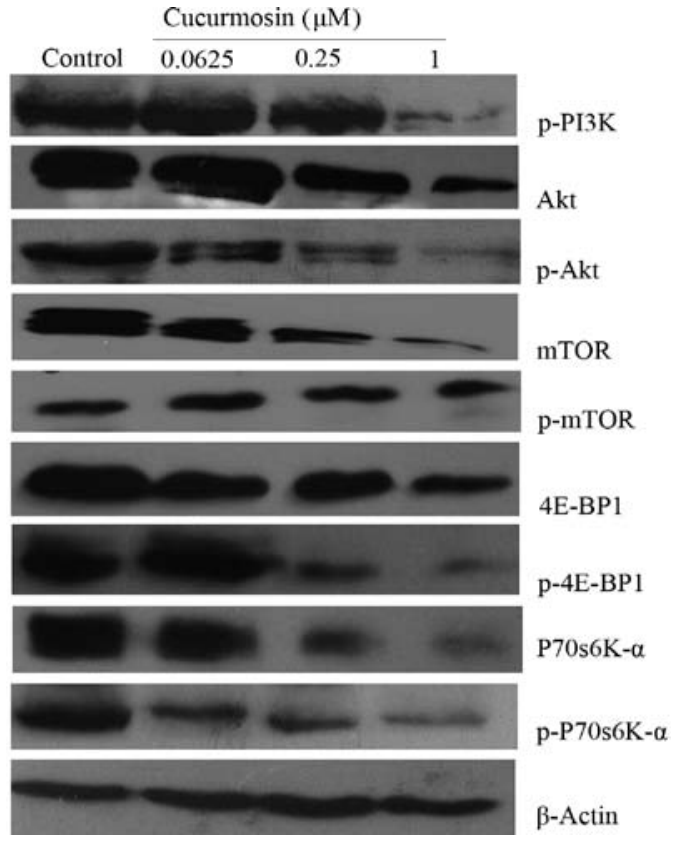

Figure 6. Cucurmosin blocks the signal transduction of the PI3K/Akt/mTOR signaling pathway via down-regulating EGFR. Cells were treated without (control) or with various concentrations of cucurmosin for $72 \mathrm{~h}$, and harvested. Total protein fractions were extracted, separated on SDS-PAGE, and exposed to specific antibodies using Western blotting as described in Materials and methods. With increasing concentrations of cucurmosin, the protein expressions of activated (phosphorylated) PI3K, total and activated (phosphorylated) Akt, total and activated (phosphorylated) mTOR, total and activated (phosphorylated) 4EBP-1 and total and activated (phosphorylated) P70s6K- $\alpha$ were gradually reduced. The results shown are representatives of 3 independent experiments.

associated with clinical prognosis, and treatment response (15), but increasing evidence suggests the dysregulation of EGFR pathways by overexpression or constitutive activation could promote tumor growth and metastasis, and that this is associated with poor prognosis and tumor aggressiveness in 


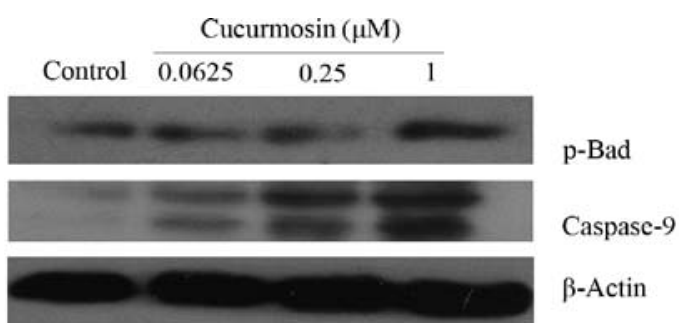

Figure 7. Cucurmosin increases activated (phosphorylated) Bad and procaspase-9, pro-apoptotic proteins of the Akt downstream targets. Cells were treated without (control) or with various concentrations of cucurmosin for $72 \mathrm{~h}$, and harvested. Total protein fractions were extracted, separated on SDS-PAGE, and exposed to specific antibodies using Western blotting as described in Materials and methods. With increasing concentrations of cucurmosin, the protein expressions of activated (phosphorylated) Bad and pro-caspase- 9 were elevated. The results shown are representatives of 3 independent experiments.

pancreatic cancer (16-20). In this study, we detected EGFR expression by Western blotting. The results show that EGFR expression was reduced after BxPC-3 cells were treated with various cucurmosin concentrations for $72 \mathrm{~h}$ (Fig. 5). This demonstrates that EGFR is an effective target for cucurmosin. To explore how cucurmosin induces the apoptosis in BxPC-3 cells via the EGFR pathway, the key components of the PI3K/ Akt/mTOR signaling pathway were detected using Western blotting. Expressions of EGFR, p-PI3K, Akt, p-Akt, mTOR, p-mTOR, P70S6K- $\alpha$, p-P70S6K- $\alpha, 4 \mathrm{E}-\mathrm{BP} 1$ and p-4E-BP1 were decreased (Fig. 6), but expressions of p-Bad and caspase-9 were increased by cucurmosin in a dose-dependent manner (Fig. 7). This finding shows that cucurmosin might induce the apoptosis of pancreatic cancer cells through inactivating the $\mathrm{PI} 3 \mathrm{~K} / \mathrm{Akt} / \mathrm{mTOR}$ signaling pathway.

Cucurmosin does not alter EGFR gene transcription in BxPC-3 cells. In a recent study, Fujita et al illustrated that the high-level expression of EGFR mRNA was correlated with shorter disease-free-survival and overall-survival after gemcitabine-based-adjuvant chemotherapy (21). To investigate whether cucurmosin can down-regulate the EGFR mRNA expression, RT-PCR was performed. Conversely, we found that EGFR mRNA expression was not changed after BxPC-3 cells were treated with various cucurmosin concentrations for $72 \mathrm{~h}$ (Fig. 8). This is explained by the function of cucurmosin, in inhibiting only protein synthesis.

\section{Discussion}

We found that cucurmosin can inhibit the proliferation of human pancreatic cancer BxPC-3 in a time and dose-dependent manner. $\mathrm{IC}_{50}$ for 24,48 and $72 \mathrm{~h}$ were $1.45 \pm 2.14,0.54 \pm 1.78$, $0.22 \pm 0.69 \mu \mathrm{M}$, respectively $(\mathrm{P}<0.05)$. The apoptosis rates without treatment or with $0.0625,0.25,1 \mu \mathrm{M}$ cucurmosin for $72 \mathrm{~h}$ were $5.31 \pm 0.21,25.17 \pm 1.32,51.79 \pm 2.32$ and $76.57 \pm 3.25 \%$, respectively $(\mathrm{P}<0.05)$. These findings show that cucurmosin inhibits the proliferation of pancreatic cancer BxPC-3 cell through the induction of apoptosis.

A comprehensive genetic analysis of 24 pancreatic ductal adenocarcinoma (PDAC) defined alterations in 12 cellsignaling pathways. The dysregulated pathways include Wnt/

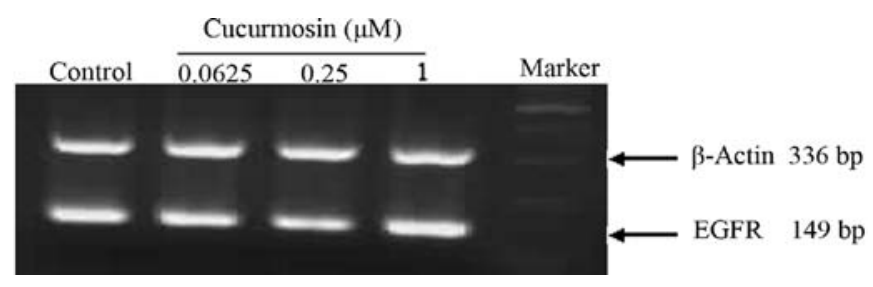

Figure 8. Cucurmosin does not affect EGFR gene transcription in pancreatic cancer BxPC-3 cells. Cells were treated without (control) or with various concentrations of cucurmosin for $72 \mathrm{~h}$, and harvested. Total-RNA was extracted. RT-PCR detected the mRNA expression of EGFR. With increasing concentrations of cucurmosin, the mRNA expression of EGFR was not altered. The figures shown are representatives of 3 independent experiments.

Notch and Hedgehog signaling, each contributing to pancreatic tumorigenesis (22). Therefore, pancreatic cancer is a multi-target disease. Moore et al demonstrated improvement in survival to 6.24 vs. 5.91 months with the combination of gemcitabine and erlotinib, a small-molecule tyrosine kinase inhibitor that targets and blocks epidermal growth factor receptor (EGFR), compared to gemcitabine alone (23). This trial rasied significant interest in targeting the EGFR signaling pathway in metastatic pancreatic cancer.

EGFR is $170 \mathrm{kDa}$ protein belonging to 1 of 4 members of the ErbB family of transmembrane tyrosine kinase growth receptors (24). Activation of EGFR in tumors results in increased cell proliferation, reduced apoptosis, increased angiogenesis, increased motility, invasion and metastasis (25). It is believed to play an integral part in tumorigenesis of multiple epithelial cancers, including pancreatic cancer (26). The EGFR over-expression is observed in 30-89\% of pancreatic cancers assayed by immunohistochemistry techniques $(27,28)$. Its expression had been shown to correlate with worse outcome and more aggressive disease in few restrospective studies (16-20). Therefore, EGFR-targeted therapy is a significant strategy.

Cucurmosin belongs to type 1 RIP and is similar to trichosanthin in structure, but the cytotoxicity of cucurmosin is more potent than trichosanthin. Cucurmosin possesses an rRNA N-glycosidase activity and inhibits protein synthesis (29). In this study, we detected the EGFR expression at the protein and mRNA level using Western blotting and RT-PCR, respectively. With increasing concentrations of cucurmosin, the EGFR expression was gradually decreased $(\mathrm{P}<0.05)$, which shows that cucurmosin can down-regulate the EGFR expression in pancreatic cancer BxPC-3 cells, and EGFR is an effective target for cucurmosin. But the mRNA expression was not changed, which demonstrates that cucurmosin only inhibits the protein synthesis and does not disturb the transcription process.

The PI3K/Akt signaling pathway is an important regulator of cell growth and survival (30). In a various types of tumors, components of this signaling pathway are activated, permitting cancer cell growth and proliferation and evasion of apoptosis, contributing to tumorigenesis (31). Once EGFR binds to the corresponding ligand, the PI3K is directly activated or is activated via Ras (32). Activation of PI3K leads to the phosphorylation of Akt/PKB. Akt promotes cell survival through effects on numerous downstream targets, including 
the inactivation of pro-apoptotic proteins such as Bad and caspase-9, or the activation of nuclear factor-kappa B (NF- $\mathrm{KB}$ ) resulting in transcription of anti-apoptotic genes (33-35). We found that expression levels of p-PI3K, Akt, p-Akt were downregulated, but the expression levels of p-Bad and caspase- 9 were elevated in response to cucurmosin treatment. This suggests that cucurmosin can inactivate the key components of the PI3K/Akt signaling pathway through inactivating EGFR. This is in accordance with a prior study, in which the EGFR inhibitor inhibited the PI3K/Akt pathway activation and induced apoptosis (36).

The mammalian target of rapamycin (mTOR) is an intracellular serine/threonine protein kinase positioned at a central point in a variety of cellular signaling cascades. EGFR and associated ligands transmit the signal to mTOR through the PI3K/Akt and Ras-Raf signaling, in particularly, the PI3K/Akt/mTOR signaling pathway (37). mTOR signals through several downstream effectors, including the 4E-BP1 (eukaryotic initiation factor 4E-binding protein) family of translational repressors and the S6Ks, to initiate ribosome translation of mRNA into protein (38). Studies showed that mTOR controls cell cycle progression which was blocked in the G0/G1 phase through its cell growth effectors S6K1 and 4E-BP1 $(39,40)$. We found the expression of mTOR, p-mTOR, P70S6K- $\alpha$, p- P70S6K- $\alpha, 4 \mathrm{E}-\mathrm{BP} 1$ and p-4E-BP1 at the protein level were decreased in a dose-dependent manner $(\mathrm{P}<0.05)$. Meanwhile, the cell cycle of pancreatic cancer BxPC-3 cell was arrested in the G0/G1 phase using a Cell Cycle Detection kit by FACSCalibur. Cucurmosin can inactivate the activity of mTOR signaling through the PI3K/Akt signaling pathway. The blockade of the cell cycle might be due to down-regulation of P70S6K- $\alpha$ and 4E-BP1.

In summary, cucurmosin can down-regulate the EGFR expression in pancreatic cancer cell. But the effect is selective and not specific because cucurmosin might down-regulate many targets. Cucurmosin induced the apoptosis of pancreatic cancer cell via inactivating the PI3K/Akt/mTOR signaling pathway. The PI3K/Akt/mTOR signaling pathway can be activated or inhibited by a lot of molecules, present on the cell membrane or in the cytoplasm, and apoptosis is a complex process controlled by a number of signaling pathways. Here, we preliminarily investigated the mechanism of the induction of apoptosis for cucurmosin and future studies will further explore this mechanism.

\section{Acknowledgements}

This study was supported by the National Science Foundation of China (no. 30772587), the Great Research Project of Fujian Medical University (no. 09ZD012) and the Natural Science Foundation of Fujian Province (nos. C0510012, 2011J01188).

\section{References}

1. Jemal A, Siegel R, Xu J and Ward E: Cancer statistics, 2010. CA Cancer J Clin 60: 277-300, 2010.

2. Schneider G, Siveke JT, Eckel F and Schmid RM: Pancreatic cancer: basic and clinical aspects. Gastroenterology 128: 1606-1625, 2005.

3. Muller MW, Friess H, Köninger J, et al: Factors influencing survival after bypass procedures in patients with advanced pancreatic adenocarcinomas. Am J Surg 195: 221-228, 2008.
4. Burris HA III, Moore MJ, Andersen J, et al: Improvements in survival and clinical benefit with gemcitabine as first-line therapy for patients with advanced pancreas cancer: a randomized trial. J Clin Oncol 15: 2403-2413, 1997.

5. Stathis A and Moore MJ: Advanced pancreatic carcinoma: current treatment and future challenges. Nat Rev Clin Oncol 7: 163-1721, 2010.

6. Barbieri L, Battelli MG and Stirpe F: Ribosome-inactivating proteins from plants. Biochim Biophys Acta 1154: 237-282, 1993.

7. Stirpe $F$ and Barbieri L: Ribosome-inactivating proteins up to date. FEBS Lett 195: 1-8, 1986.

8. Van Damme Els JM, Hao Q, Chen Y, et al: Ribosome-inactivating proteins: a family of plant proteins that do more than inactivate ribosomes. Crit Rev Plant Sci 20: 395-465, 2001.

9. Hou XM, Chen M, Xie JM, et al: Crystallization and preliminary crystallographic studies of cucurmosin 2 , a ribosome-inactivating protein from the sarcocarp of Cucurbita moschata. J Struct Chem 28: 215-217, 2009.

10. Hou X, Chen M, Chen L, et al: X-ray sequence and crystal structure of luffaculin I, a novel type I ribosome-inactivating protein. BMC Struct Biol 7: 29, 2007.

11. Chen MH, Xie JM, Ye X: Antitumor activity of squash protein and use thereof. PRC Patent Application CN1603340A, published April 6, 2005.

12. Yin Q, Huang H, Xie J, et al: Effect of cucurmosin on apoptosis in human pancreatic cancer cell line SW1990. Zhon Guo Pu Wai Ji Chu Yu Lin Chuang Za Zhi 18: 381-384, 2011 (In Chinese).

13. Xu C, Huang $\mathrm{H}$, Chen M, et al: Cytotoxic and chemosensitivity enhancement effect of cucurmosin on pancreatic cancer cell line PANC-1 in vitro. Zhong Guo Pu Tong Wai Ke Za Zhi 18: 233-236, 2009 (In Chinese).

14. Sun J, Xie J,Zhang K, et al: Molecular mechanism of the induction of apoptosis by synergizing cucurmosin with ST1571 against K562 cell. Acta Fujian Medical University 42: 30-32, 2008.

15. Lozano-Leon A, Perez-Quintela BV, Iglesias-Garcia J, et al: Clinical relevance of epidermal growth factor receptor (EGFR) alterations in human pancreatic tumors. Oncol Rep 26: 315-320, 2011.

16. Kuniyasu H, Abbruzzese JL, Cleary KR and Fidler IJ: Induction of ductal and stromal hyperplasia by basic fibroblast growth factor produced by human pancreatic carcinoma. Int J Oncol 19: 681-685, 2001.

17. Faller Ba and Burtness B: Treatment of pancreatic cancer with epidermal growth factor receptor-targeted therapy. Biologics 3: 419-428, 2009.

18. Ueda S, Ogata S, Tsuda H, et al: The correlation between cytoplasmic overexpression of epidermal growth factor receptor and tumor aggressiveness: poor prognosis in patients with pancreatic ductal adenocarcinoma. Pancreas 29: e1-e8, 2004.

19. Bloomston M, Bhardwaj A, Ellison EC and Frankel WL: Epidermal growth factor receptor expression in pancreatic carcinoma using tissue microarray technique. Dig Surg 23: 74-79, 2006.

20. Takikita M, Altekruse S, Lynch CF, et al: Associations between selected biomarkers and prognosis in a population-based pancreatic cancer tissue microarray. Cancer Res 69: 2950-2955, 2009.

21. Fujita H, Ohuchida K, Mizumoto K, et al: High EGFR mRNA expression is a prognostic factor for reduced survival in pancreatic cancer after gemcitabine-based-adjuvant chemotherapy. Int J Oncol 38: 629-641, 2011.

22. Jones S, Zhang X, Parsons DW, et al: Core signaling pathways in human pancreatic cancers revealed by global genomic analyses. Science 321: 1801-1806, 2008.

23. Moore MJ, Goldstein D, Hamm J, et al: Erlotinib plus gemcitabine compared with gemcitabine alone in patients with advanced pancreatic cancer: a phase III trial of the National Cancer Institute of Canada Clinical Trials Group. J Clin Oncol 25: 1960-1966,2007.

24. Zhang Y,Banerjee S, Wang Z, et al: Antitumor activity of epidermal growth factor-related protein is mediated by inactivation of ErbB receptors and nuclear factor-kappaB in pancreatic cancer. Cancer Res 66: 1025-1032, 2006.

25. Kopp R, Rothbauer E, Ruge M, et al: Clinical implications of the EGF receptor/ligand system for tumor progression and survival in gastrointestinal carcinomas: evidence for new therapeutic options. Recent Results Cancer Res 162: 115-132, 2003.

26. Lemoine NR, Hughes CM, Barton CM, et al: The epidermal growth factor receptor in human pancreatic cancer. J Pathol 166: 7-12, 1992 . 
27. Fjallskog ML, Lejonklou MH, Oberg KE, et al: Expression of molecular targets for tyrosine kinase receptor antagonists in malignant endocrine pancreatic tumors. Clin Cancer Res 9: $1469-1473,2003$.

28. Tobita K, Kijima H, Dowaki S, et al: Epidermal growth factor receptor expression in human pancreatic cancer: Significance for liver metastasis. Int J Mol Med 11: 305-309, 2003.

29. Hou X, Meehan EJ, Xie J, et al: Atomic resolution structure of cucurmosin, a novel type I ribosome-inactivating protein from the sarcocarp of Cucurbita moschata. J Struct Biol 164: 81-87, 2008.

30. Vivanco I and Sawyers CL: The phosphatidylinositol 3-kinase AKT pathway in human cancer. Nat Rev Cancer 2: 489-501, 2002

31. Shaw RJ and Cantley LC: Ras, PI3K and mTOR signaling controls tumor cell growth. Nature 441: 424-430, 2006.

32. Cantley LC: The phosphatidylinositol 3-kinase pathway. Science 296: 1655-1657, 2002.

33. Fahy BN, Schlieman MG, Virudachalam S and Bold RJ: Inhibition of Akt abrogates chemotherapy-induced NF-kappaB survival mechanisms: implications for therapy in pancreatic cancer. J Am Coll Surg 198: 591-599, 2004.

34. Cardone MH, Roy N, Stennicke HR, et al: Regulation of cell deathprotease caspase-9 by phosphorylation. Science 282: 1318-1321, 1998.
35. Datta SR, Dudek H, Tao X, et al: Akt phosphorylation of BAD couples survival signals to the cell-intrinsic death machinery. Cell 91: 231-241, 1997.

36. Bruns CJ, Solorzano CC, Habrison MT, et al: Blockade of epidermal growth factor receptor signaling by a novel tyrosine kinase inhibitor leads to apoptosis of endothelial cells and therapy of human pancreatic carcinoma. Cancer Res 60: 2926-2935, 2000.

37. Yuan R, Kay A, Berg WJ and Lebwohl D: Targeting tumorigenesis: development and use of mTOR inhibitors in cancer therapy. J Hematol Oncol 2: 45, 2009.

38. Sarbassov DD and Sabatini DM: Redox regulation of the nutrientsensitive raptor-mTOR pathway and complex. J Biol Chem 280: 39505-39509, 2005.

39. Fingar DC, Richardson CJ, Tee AR, et al: mTOR controls cell cycle progression through its cell growth effectors S6K1 and 4E-BP1/eukaryotic translation initiation factor 4E. Mol Cell Biol 24: 200-216, 2004

40. Hidalgo $M$ and Rowinsky EK: The rapamycin-sensitive signal transduction pathway as a target for cancer therapy. Oncogene 19: 6680-6686, 2000. 